\title{
The Consideration of Gender in the Process of Appointing Judges to the European Court of Human Rights
}

\author{
Alastair Mowbray: Professor of Public Law, University of Nottingham \\ (C) A.R. Mowbray
}

This is a pre-copy-editing, author-produced PDF of an article accepted for publication in Human Rights Human Rights Law Review. 8(3), 549-559 following peer review. The definitive publisher-authenticated version is available online at: http://hrlr.oxfordjournals.org/cgi/reprint/ngn012? ijkey=Mz1kskYwvTnLaQQ\&keytype=ref $]$.

The Grand Chamber of the European Court of Human Rights ${ }^{1}$ has just delivered a landmark Advisory Opinion ${ }^{2}$ on the legality of the Parliamentary Assembly's refusal to consider male-only shortlists of judicial nominees. This is the first occasion on which the Court, in both its part-time and full-time manifestations, has given a substantive answer to such a request by the Committee of Ministers, under Article 47 of the European Convention on Human Rights ${ }^{3}$. In 2004 the Grand Chamber held that a request for an Advisory Opinion concerning the status of the complaints system set up by members of the Commonwealth of Independent States, following the collapse of the former USSR, to which some parties to the ECHR belong fell outside the Court's jurisdiction. ${ }^{4}$ Hence it has taken 38 years for the Court to be granted an opportunity to exercise its Advisory Opinion responsibility since Protocol 2 conferred the power on the original Court.

\footnotetext{
${ }^{1}$ Hereafter the Court.

2 "Advisory Opinion on certain legal questions concerning the lists of candidates submitted with a view to the election of judges to the European Court of Human Rights", 12 February 2008: available from the HUDOC database at www.echr.coe.int .

${ }^{3}$ Hereafter the ECHR or Convention.

4 "Decision on the competence of the Court to give an Advisory Opinion", 2 June 2004. See further, A. Mowbray, "An Examination of the Work of the Grand Chamber of the European Court of Human Rights” [2007] Public Law 507 at 523-526.
} 
As is well-known ${ }^{5}$ the process of appointing judges to the Court involves both member States and the Parliamentary Assembly. Each member State nominates three candidates, whom it considers satisfy the criteria for office laid down by Article 21 of the Convention: namely being of "high moral character" and possessing "the qualifications required for high judicial office or be jurisconsults of recognised competence". The Parliamentary Assembly then elects the person who will sit as the national judge for that State, under Article 22(1) of the ECHR. However, the Convention's limited elaboration of the appointments process has been supplemented by the Parliamentary Assembly developing increasingly rigorous procedures for scrutinising nominees and adding further criteria of eligibility for nominees. For example, nominees to the full-time Court are asked to submit standardised $C V s$ and be interviewed by members of a sub-committee of the Parliamentary Assembly. In 2004 the Parliamentary Assembly approved Resolution 1366 which provided:

\section{Candidates for the European Court of Human Rights}

3. The Assembly decides not to consider lists of candidates where:

i. the areas of competence of the candidates appear to be unduly restricted;

ii. the list does not include at least one candidate of each sex;

iii. the candidates:

a. do not appear to have sufficient knowledge of at least one of the two official languages, or

b. do not appear to be of the stature to meet the criteria in Article 21, paragraph 1, of the European Convention on Human Rights.

4. The Assembly continues to believe that the process of interview provides additional insight into the qualities of the candidates and decides:

i. that nominated candidates should be informed as far as possible of the purpose of the interview and procedures for its conduct;

ii. that alternative locations for interviews should be considered if there is a valid reason for holding interviews outside Strasbourg and Paris;

iii. that further staggering or additional sessions of the sub-committee might permit an extension of the time available for each interview;

\footnotetext{
${ }^{5}$ See A. Mowbray, Cases \& Materials on the ECHR $2^{\text {nd }} e d .$, (Oxford: OUP.2007) at pp.15-17.
} 
iv. that the political groups, when nominating their representatives to the sub-committee, should aim to include at least $40 \%$ women, which is the parity threshold deemed necessary by the Council of Europe to exclude possible gender bias in decision-making processes;

v. that candidates should be made aware of the criteria employed by the sub-committee in reaching its decision;

vi. that one of the criteria used by the sub-committee should be that, in the case of equal merit, preference should be given to a candidate of the sex under-represented at the Court;

vii. that a fair and efficient interview process requires a continuous process of training and reassessment of the members and staff involved in selection panels;

viii. that the obligation to promote an open and transparent process might require the subcommittee to give reasons for its recommendations and ranking of candidates;

ix. that it would be desirable to provide timely feedback to both the individual candidate and the nominating state.

7. The Assembly decides to investigate at national and European level what obstacles currently exist to the nomination of women candidates, what measures could be taken to encourage female applicants, and to consider setting targets for achieving greater gender equality in the composition of the Court.

A key element of the Resolution was the Parliamentary Assembly's desire to increase the proportion of female judges on the Court. At present approximately a third of whom are female.

During 2004 the Parliamentary Assembly also invited the Committee of Ministers to formally amend Article 22 of the ECHR to require member States to include at least one candidate of each sex in every nomination list. $^{6}$ But, the Committee of Ministers declined to include such an amendment in the text of Protocol 14, reforming the Strasbourg enforcement system. ${ }^{7}$

7. ... The Committee of Ministers, recalling its constant position originally expressed as early as May 1997, wishes to make it clear that it fully shares the Assembly's determination to secure a proper balance of the sexes in the composition of the Court and agrees therefore that lists of candidates should as a general rule contain at least one candidate of each sex.

8. The Committee nonetheless believes that circumstances may exceptionally arise in which, as a result of the correct application of the other five criteria, a Contracting Party may find itself obliged to submit a list containing candidates of only one sex in derogation from that rule, and that it would therefore be undesirable to give such a rule binding force under the Convention. In this context, the Committee draws attention to the danger that such an obligation could under certain circumstances give rise to difficulties in satisfying the requirements of Article 21 of the Convention.

\footnotetext{
${ }^{6}$ Recommendation 1649 (2004).

${ }^{7}$ On these reforms see, A. Mowbray, "Protocol 14 to the European Convention on Human Rights", 4(2) Human Rights Law Review 331 (2004).
} 
9. The Committee of Ministers therefore invites the Assembly to consider the possibility of modifying its own rules in order to allow exceptional derogation from the rule where the authorities of the Contracting Party concerned present convincing arguments to the Committee of Ministers and the Assembly to the effect that, in order to respect the requirements concerning the individual qualifications of candidates, it could not do otherwise than to submit a single-sex list. ...

The Parliamentary Assembly responded by passing Resolution 1426 (2005)

which stated that:

3. The Assembly notes that women are clearly still under-represented in the Court today, as only 11 of the 44 judges currently in office are women.

4. The wording of paragraph 3.ii of [Resolution 1366 (2004)] effectively excludes any consideration of an all-female list of candidates, even if this would obviously contribute to furthering the Assembly's purpose of achieving a more balanced representation of both sexes in the Court.

5. Accordingly, the Assembly decides to introduce a special rule for considering candidatures for the European Court of Human Rights regarding the under-represented sex in the Court and to amend paragraph 3.ii of Resolution 1366 (2004) as follows:

'3. The Assembly decides not to consider lists of candidates where:

(...)

ii. the list does not include at least one candidate of each sex, except when the candidates belong to the sex which is under-represented in the Court, that is the sex to which under $40 \%$ of the total number of judges belong.

So the Parliamentary Assembly re-stated its opposition to single sex shortlists, unless they were all female.

In March 2004 and September 2006 the government of Malta submitted allmale shortlists of nominees to replace the incumbent, male, Maltese judge (Giovanni Bonello). The Parliamentary Assembly refused to elect a judge in respect of Malta as the shortlists did not contain any female nominees as required by Resolutions 1366 and 1426. The Deputy Prime Minister of Malta wrote, on 22 February 2007, to the President of the Parliamentary Assembly (Rene van der Linden):

Nowhere in the Convention is it stipulated that one candidate belonging to the sex which is under represented in the Court must feature in the list.

Besides, the Maltese Government acted in the most transparent manner in preparing the submitted list. It first of all issued a public call for nominations - a procedure which has not been followed in a number of other member states of the Council of Europe. Only two female

\footnotetext{
${ }^{8} \mathrm{CM} / \mathrm{AS}(2005) \operatorname{Rec} 1649$ final.
} 
candidates applied. At the same time the entire composition of the three-member Constitutional Court of Malta - all males - applied for the post.

Upon examination it transpired that:

a) the two female candidates did not possess the necessary experience in the field of human rights as required by paragraph $19 \mathrm{ii}$ of the Parliamentary Assembly's Recommendation 1649 (2004)

b) secondly, and without prejudice to paragraph (a), the three members selected, had vast experience of the subject (including at least twenty years' experience in human rights law) and were by far more qualified than any other candidate, male or female.

The process which led to the list of candidates submitted by Malta reflected, therefore, "the principles of democratic procedure, the rule of law, non-discrimination, accountability and transparency" (cf. Rec. 1649 (2004)).

The Maltese Government has therefore submitted a list which is in conformity with the European Convention on Human Rights; it is respectfully submitted that this list can only be refused if it does not conform with the criteria listed in article 21 of the Convention and not on gender-related issues which are not mentioned or covered by the Convention; so much so that recently the Parliamentary Assembly requested the Committee of Ministers to amend the Convention to oblige a High Contracting Party to submit the name of a candidate from the sex under-represented in the Court (female). This request was rejected, which therefore confirms the position of the Maltese Government that the Assembly has no right under the Convention as it stands today, to reject any list of candidates on gender issues.

Besides, as I have pointed out, the Maltese Government did its utmost to find a female candidate with the required expertise by issuing a public call for nominations. The fact that in Malta only in recent years has the number of female lawyers increased was completely ignored by the Assembly; and a one-size-fits-all rule, which is alien to the provisions of the Convention, was applied.

In the circumstances I suggest that a proper dialogue be opened between the two sides to solve the current impasse. I assure you that had there been other female candidates who satisfied the criteria of art 21 , and who were as capable as or more capable than the three judges nominated, they would certainly have been included in the list.

Finally I firmly believe that the Convention can only be amended by the unanimous consent of the High Contracting Parties and not through Resolutions of any body of the Council of Europe.

In this context, I respectfully submit that since your refusal of the list on gender-related issues raises a matter of interpretation of article 21 and 22 of the Convention, the question should be referred to the Committee of Ministers by both sides; then the Committee may request an Advisory opinion of the European Court of Human Rights under article 47 of the Convention. The Maltese Government is ready to abide by the conclusions of such an opinion, and so I believe would be the Assembly...

During March 2007, the Legal Affairs and Human Rights Committee of the

Parliamentary Assembly proposed an amendment to the above Resolutions. In "exceptional circumstances", agreed upon by a two-thirds majority of the Ad hoc Sub-Committee on the Election of Judges to the European Court of Human Rights (of the Parliamentary Assembly), all-male shortlists would be considered by the Parliamentary Assembly. However, the proposed amendment was subject to a critical report by the Parliamentary Assembly's Committee on Equal Opportunities for 
Women and Men. ${ }^{9}$ The report stated that only Malta had found it "difficult" to comply with the existing requirement that all shortlists should contain at least one woman.

12. Malta is not the smallest member state of the Council of Europe by any means. It has nearly 400.000 inhabitants, half of them women. There are two female judges and six female magistrates in Malta, and many more female advocates (the current judge on the Court, Mr Giovanni Bonello, was an advocate in private practice before he was elected). The country thus has a sufficiently large pool of highly qualified female potential candidates. However, even if it had not, it could choose a well-qualified female candidate from another country (the United Kingdom and Italy would spring to mind, the two countries which most influenced Malta's legal tradition over the centuries). In fact, Malta could even choose amongst the most famous human rights lawyers globally, from Mary Robinson over Asma Jahangir to Shirin Ebadi. These candidates would certainly not be less qualified than the three male candidates Malta has proposed so far.

13. Furthermore, much smaller countries than Malta have included qualified women candidates on their candidate lists. In fact, in several cases, these candidates were even elected judges to the European Court for Human Rights, such as Mrs Isabelle Berro-Lefèvre for Monaco (population: around 32.000) and Mrs Antonella Mularoni for San Marino (population: around 30.000). The true impediment to the inclusion of a qualified woman candidate on the list submitted by Malta thus appears not to be a lack of qualified female candidates, but a lack of respect for the principle of gender equality.

19. In addition, the draft resolution submitted by the Committee on Legal Affairs and Human Rights is very widely worded, leaving it entirely to the (male dominated) Ad hoc Sub-Committee and the Committee on Legal Affairs and Human Rights to decide what the 'exceptional circumstances' allowing all-male candidate lists should comprise. Since both of these bodies consider that Malta's current case poses such 'exceptional circumstances' - although Malta is a country with a population of nearly 400.000 with plenty of well-qualified female potential candidates, which also has the possibility of fielding a non-Maltese female candidate - one wonders which other countries would have the back-door opened to them to present all-male candidate lists, returning the Assembly to the status quo ante when it often could not elect a female judge even if it wanted to!

Subsequently, on 17 April 2007, the Parliamentary Assembly, by 41 votes to 17, decided to reject the proposed amendment to the existing gender requirements for national shortlists of nominees. In the light of that decision the President of the Parliamentary Assembly wrote, on 25 April, to the Maltese Deputy Prime informing him that the Maltese list of candidates did not meet the requirements of the Parliamentary Assembly. After further correspondence between those two office holders re-stating their respective positions, the Maltese Permanent Representative to the Council of Europe requested that the Committee of Ministers seek an Advisory

\footnotetext{
${ }^{9}$ Doc 11208.
} 
Opinion from the Court on these matters. On 17 July 2007 the Chairperson of the Ministers' Deputies requested the Court to give an Advisory Opinion on the following questions:

(a) can a list of candidates for the post of judge at the European Court of Human Rights, which satisfies the criteria listed in Article 21 of the Convention, be refused solely on the basis of gender-related issues?

(b) are Resolution 1366 (2004) and Resolution 1426 (2005) in breach of the Assembly's responsibilities under Article 22 of the Convention to consider a list, or a name on such list, on the basis of the criteria listed in Article 21 of the Convention?

The Court invited all the member States and the Parliamentary Assembly to submit written comments on the request. Thirteen States ${ }^{10}$ and the Parliamentary Assembly responded. In October 2007, member States were also asked to supply written details of any domestic rules designed to ensure the presence of women or the under-represented gender on their highest national courts. Thirty seven replies were received. Taking account of the written submissions the President of the Court determined that there was no need for an oral hearing.

The information from the member States disclosed that only three of them had legislation requiring egalitarian representation of both sexes in their highest courts. ${ }^{11}$ But others had legislation or action plans designed to increase the numbers of senior female judges. The Grand Chamber also noted that only two international courts, the International Criminal Court and the African Court on Human and Peoples' Rights, have (non-binding) rules designed to promote a gender balance in their composition.

\footnotetext{
${ }^{10}$ Austria, Czech Republic, France, Georgia, Malta, Monaco, Portugal, Slovakia, Slovenia, Spain, Switzerland, Turkey and the United Kingdom.

${ }^{11}$ Austria, Belgium and Latvia.
} 
The preliminary issue for the Grand Chamber was whether the questions posed were within its Advisory Opinion jurisdiction. The submissions of Austria and Spain had disputed the Court's jurisdiction as the governments considered the questions to be political. The French submission contended that the Court did not have authority to examine the compatibility of Parliamentary Assembly resolutions with the Convention. Regarding the Committee of Minister's first question the Grand Chamber held that:

...The question therefore concerns the rights and obligations of the Parliamentary Assembly in the procedure for electing judges, as derived from Article 22 in particular and from the Convention system in general. Accordingly, whatever its implications, it is of a legal character and as such falls within the scope of the Court's jurisdiction under Article $47 \S 1$ of the Convention. Furthermore, it does not appear - nor has any government claimed - that the opinion requested concerns one of the matters excluded from the Court's jurisdiction by the second paragraph of Article 47. Consequently, the Court has jurisdiction to answer the first question. ${ }^{12}$

As to the second question the Grand Chamber doubted whether it fell within its jurisdiction, but, given the Court's answer to the first question, it was not necessary to provide a response.

Regarding the merits of the first question the Grand Chamber ruled that whilst States were bound to ensure that all the candidates nominated met the formal criteria laid down in Article 21, the States could also take into account other criteria; such as a balance between the sexes or different branches of the legal profession. Likewise:

It is obvious too that the Assembly may take account of additional criteria which it considers relevant for the purposes of choosing between the candidates put forward by a Contracting Party and may, as it has done in a bid to ensure transparency and foreseeability, incorporate those criteria in its resolutions and recommendations. Indeed, neither Article 22 nor the Convention system sets any explicit limits on the criteria which can be employed by the Parliamentary Assembly in choosing between the candidates put forward. ${ }^{13}$

\footnotetext{
${ }^{12}$ Supra n. 2 at para. 38.

${ }^{13}$ Ibid. at para. 45.
} 
But, the Grand Chamber believed that the Parliamentary Assembly's gender criterion was different from the others articulated by that body (e.g. candidates' linguistic skills) due to the former's "lack of an implicit link with the general criteria concerning judges' qualifications laid down in Article 21(1)."14 The Grand Chamber noted the "far-reaching consensus" regarding the need to achieve gender balance within national and international public organisations. However, the Committee of Ministers had decided not to amend the Convention to require all nomination lists to contain at least one candidate of each gender.

51. In the Court's view, the Contracting Parties, which alone have the power to amend the Convention, have thus set the boundaries which the Assembly may not overstep in its pursuit of a policy aimed at ensuring that the lists include a candidate of the under-represented sex: such a policy must not have the effect of making it more difficult for Contracting Parties to put forward candidates who also satisfy all the requirements of Article $21 \S 1$, which are accordingly to be given primary consideration....

The Grand Chamber further observed that the Committee of Ministers had asked the Parliamentary Assembly to revise its policy so as to permit, in exceptional cases, the submission of male-only nomination lists by States. The Grand Chamber identified States with small legal professions as potentially falling within the exceptional category.

Without directly referring to the Report of the Parliamentary Assembly's Committee on Equal Opportunities for Men and Women ${ }^{16}$, the Grand Chamber firmly rejected the Report's proposition that small member States could meet the Assembly's gender criterion by nominating foreign-national female candidates.

...These States must not be placed in a position where, in order to fulfil the criterion concerning the sex of candidates, they can only nominate candidates

\footnotetext{
${ }^{14}$ Ibid. para 48 .

${ }^{15}$ Ibid. Para 51

${ }^{16}$ Supra n.9.
} 
who satisfy the criteria of Article $21 \S 1$ if they choose non-nationals. Although useful in certain cases the latter option, were it to be imposed, would need to be approached with caution from the point of view of respecting States' sovereignty in the matter. It would be unacceptable for a State to be forced to nominate non-national candidates solely in order to satisfy the criterion relating to a candidate's sex, which is not enshrined in the Convention. Furthermore, this would be liable to produce a situation where the elected candidate did not have the same knowledge of the legal system, language or indeed cultural and other traditions of the country concerned as a candidate from that country. Indeed, the main reason why one of the judges hearing a case must be the "national judge", a rule that dates back to the beginnings of the Convention and is today enshrined in Article $27 \S 2$, is precisely to ensure that the judges hearing the case are fully acquainted with the relevant domestic law of the respondent State and the context in which it is set. Accordingly, it would be incompatible with the Convention to require a State to nominate a candidate of a different nationality solely in order to achieve a gender balance. ${ }^{17}$

The Grand Chamber concluded that it was not possible to answer the first question by

a simple "yes" or "no" reply. Instead the Grand Chamber responded:

...In any event it is clear that, in not allowing any exceptions to the rule that the under-represented sex must be represented, the current practice of the Parliamentary Assembly is not compatible with the Convention: where a Contracting Party has taken all the necessary and appropriate steps with a view to ensuring that the list contains a candidate of the under-represented sex, but without success, and especially where it has followed the Assembly's recommendations advocating an open and transparent procedure involving a call for candidatures..., the Assembly may not reject the list in question on the sole ground that no such candidate features on it. Accordingly, exceptions to the principle that lists must contain a candidate of the under-represented sex should be defined as soon as possible.

Regarding the underlying issue of seeking to achieve a balanced representation of the sexes on the Court both the Parliamentary Assembly and the Committee of Ministers were in public agreement on the desirability of that goal. Indeed, over twenty years ago the Court held that:

...the advancement of the equality of the sexes is today a major goal in the member States of the Council of Europe. This means that very weighty reasons would have to be advanced before a difference of treatment on the ground of sex could be regarded as compatible with the Convention. ${ }^{18}$

\footnotetext{
${ }^{17}$ Supra n. 2 at para. 52.

${ }^{18}$ Abdulaziz, Cabales and Balkandali v UK, A.94 at para. 78.
} 
But, the Parliamentary Assembly and the Committee of Ministers disagreed as to the means of securing that aim. The former wanted the Convention amended to oblige States to submit nomination lists containing candidates from both sexes. That proposal was not accepted by the Committee of Ministers and the Parliamentary Assembly's contemporary policy of refusing to consider male-only shortlists led to the request for the Advisory Opinion. The latter disclosed that from a legal viewpoint the States are the dominant actors in determining the eligibility criteria for appointment to the Court, via their power to set the text of the Convention and its amending Protocols. The Court, as a judicial body, had to accord priority to the wording of the Convention over the eligibility policy of the Parliamentary Assembly. Furthermore, it appears that the Court was not convinced by the Assembly's Equal Opportunities Committee's view that small States could nominate non-national female candidates if they could not find suitably qualified female nationals. Knowledge of the relevant member State and its legal system were more important to the proper functioning of the Convention than the gender of the Strasbourg judges. One may hypothesise that micro and small European member States could have particular local values and conditions that non-national are unaware of, but this is becoming increasingly less likely in our globalised world, let alone in a single continent. However, States are wedded to the formal notion of sovereign equality and equal representation via national judges.

Given the Court's Advisory Opinion, the Parliamentary Assembly will now have to elaborate when, exceptionally, all-male shortlists may be considered. The Grand Chamber has indicated, in the Advisory Opinion, that the basic requirement for any member State seeking to justify such a shortlist will be that a publicly advertised, open, and transparent national selection process has failed to produce a suitably 
qualified female candidate. Noting the diverse contributors to this journal and the popularity of undergraduate and post-graduate ECHR modules with both female and male students from many European (and other) States at Nottingham University (and at comparable universities across the continent) there ought to be increasing numbers of well qualified candidates from both sexes for States to nominate. 